\title{
Expression of vascular endothelial growth factor (VEGF) in equine sarcoid
}

\author{
Manuela Martano* ${ }^{*}$, Karen Power, Brunella Restucci, Ilaria Pagano, Gennaro Altamura, Giuseppe Borzacchiello \\ and Paola Maiolino
}

\begin{abstract}
Background: Sarcoids are the mostcommon skin tumors in horses, characterized by rare regression, invasiveness and high recurrence following surgical intervention and Delta Papillomaviruses are widely recognized as the causative agents of the disease. In order to gain new insights into equine sarcoid development, we have evaluated, in 25 equine sarcoids, by immunohistochemistry and western blotting analysis, the expression levels of VEGF, Ki67 and bcl-2. Moreover, we have measured microvessel density and specific vessel parameters.

Results: All sarcoid samples showed a strong and finely granular cytoplasmatic staining for VEGF in the majority (90\%) of keratinocytes, sarcoid fibroblasts and endothelial cells. Numerous small blood vessels, immunostained with Von Willebrand factor, often appeared irregular in shape and without a distinct lumen, with mean values of microvessel area and perimeter lower than normal. Moreover, in all sarcoid samples, Ki67 immunoreactivity was moderately positive in 5-10\% of dermal sarcoid fibroblasts, while Bcl 2 immunoreactivity was detected in $52 \%$ of the sarcoid samples, with a weak staining in $20-50 \%$ of dermal sarcoid fibroblasts. Biochemical analysis was consistent with immunohistochemical results.
\end{abstract}

Conclusions: This study has provided evidence that in equine sarcoid: VEGF was strongly expressed; the increased number of vessels was not associated with their complete maturation, probably leading to a hypoxic condition, which could increase VEGF synthesis; the levels of sarcoid fibroblasts proliferation were very low. Concluding, VEGF may have a role in equine sarcoid development, not only through the increase of angiogenesis, but also through the control of sarcoid fibroblast activity.

Keywords: Angiogenesis, BPV, Equine sarcoid, VEGF

\section{Background}

Sarcoids are the most common skin tumors in horses [1-3], with prevalence rates ranging from 12.9 to $67 \%$ of all equine tumors $[4,5]$. They appear as benign fibroblastic skin tumors, and are characterized by rare regression, invasiveness and high recurrence following surgery [6-8]. Delta Papillomaviruses (Bovine Papillomavirus 1, Bovine Papillomavirus 2 and Bovine Papillomavirus 13) [9-11] are involved in the pathogenesis of this tumor, mainly through the biological activity of the E5 oncogene. It has also been reported that BPV alters DNA methylation status and oxidative stress parameters $[12,13]$.

* Correspondence: manuela.martano@unina.it

Department of Veterinary Medicine and Animal Productions, Naples

University "Federico II", Via F. Delpino 1, 80137 Naples, Italy
Moreover, equine sarcoid may be considered one of the main long-term complications in the wound healing process of the horse [5, 14], consequent to abnormal fibroblast proliferation and changes in dynamics of the extracellular matrix (ECM) and its main components [15]. Altered turnover of the ECM deposition and degradation, as result of an altered expression of matrix metalloproteinases (MMPs) and tissue inhibitor of metalloproteinases (TIMPs), were reported as basic mechanism for these changes [15]. ECM remodeling is strictly correlated to angiogenesis [16], as MMPs production is stimulated by many of the same factors (VEGF; tumor necrosis factor alpha; basic fibroblast growth factor) implicated in endothelial migration and formation of new capillaries (angiogenesis) [17]. VEGF, also known as vascular permeability factor (VPF), is a member of the platelet-derived growth factor (PDGF) family of growth factors, having a potent angiogenic activity and an

(c) The Author(s). 2018 Open Access This article is distributed under the terms of the Creative Commons Attribution 4.0 International License (http://creativecommons.org/licenses/by/4.0/), which permits unrestricted use, distribution, and

reproduction in any medium, provided you give appropriate credit to the original author(s) and the source, provide a link to the Creative Commons license, and indicate if changes were made. The Creative Commons Public Domain Dedication waiver (http://creativecommons.org/publicdomain/zero/1.0/) applies to the data made available in this article, unless otherwise stated. 
important role in the modulation of ECM homeostasis and remodeling $[18,19]$. It is involved in numerous physiological and pathological processes, such as embryonic development [20], bone formation [21] wound healing [22] and cancer [23-27], in which it is up-regulated by oncogene expression, growth factors and hypoxia [28-30]. Moreover, it has been reported that Human Papillomavirus type 16 E6 and E7 oncoproteins may contribute to tumor angiogenesis by direct activation of the VEGF gene promoter in human lung and cervical carcinoma [31-33].

Although the general role of VEGF in angiogenic processes has been intensively studied [23-27], its specific function in sarcoid development has not been investigated, so far. In this regard, the aim of this study was to evaluate in a subset of equine sarcoids, the levels of VEGF expression in association with angiogenesis (evaluation of microvessel density and specific vessel parameters), and with Ki67 and bcl-2 expression.

\section{Results}

\section{Histological features}

Haematoxylin and eosin staining of examined sarcoids $(n=25)$ showed the typical histological changes in their epidermal (when present) and dermal component, as reported by Martano et al. (2016) [15], such as: hyperkeratosis and epidermal hyperplasia often accompanied by rete pegs; dermal fibroblasts usually oriented perpendicular to the basal epidermal layer in a 'picket fence' pattern; abundant ECM; numerous small vessels irregular in shape.

\section{Immunohistochemical and biochemical results}

The expression patterns of VEGF, Ki67 and bcl-2 in 25 equine sarcoids and 5 normal skin samples are summarized in Table 1.

In all normal skin samples, weak granular cytoplasmatic VEGF immunopositivity was detected predominantly in the basal layer of normal epidermis (Fig. 1a), while normal fibroblasts were negative. Ki67 immunostaining was moderate and restricted to the basal layer of epidermis and hair follicle (Fig. 1b), while bcl-2 immunostaing was very weak and in 2/5 samples was negative (Fig. 1c). Moreover, in normal skin samples, blood vessels, immunostained with vWF, appeared regular in shape and size, with a distinct lumen (Fig. 1d).

In all sarcoid samples the majority (90\%) of keratinocytes, neoplastic fibroblasts and endothelial cells showed a strong and finely granular cytoplasmatic staining for VEGF (Fig. 2a; secondary-only negative control Fig. 2b) and Ki67 immunoreactivity was strong in the majority (90\%) of epidermal and hair follicle basal cells and endothelial cells, while only $5-10 \%$ of neoplastic dermal fibroblasts were moderately positive (Fig. 2c; secondary-only negative control Fig. 2d). In 18 out of 25 sarcoid samples (72\%) bcl-2 immunoreactivity
Table 1 Immunoreactivity scoring of VEGF, Ki67 and Bcl2 in 25 equine sarcoid samples and 5 equine normal skins

\begin{tabular}{|c|c|c|c|c|}
\hline \multirow[t]{2}{*}{ Samples } & \multirow[t]{2}{*}{ Location } & \multirow{2}{*}{$\begin{array}{l}\text { VEGF } \\
\text { Staining } \\
\text { Intensity }\end{array}$} & \multirow{2}{*}{$\begin{array}{l}\text { Ki67 } \\
\text { Staining } \\
\text { Intensity }\end{array}$} & \multirow{2}{*}{$\begin{array}{l}\text { bcl-2 } \\
\text { Staining } \\
\text { Intensity }\end{array}$} \\
\hline & & & & \\
\hline S1 & neck & ++ & + & + \\
\hline S2 & $\operatorname{limb}$ & ++ & + & $+/-$ \\
\hline S3 & $\begin{array}{l}\text { Pectoral } \\
\text { region }\end{array}$ & ++ & + & + \\
\hline S4 & $\operatorname{limb}$ & ++ & + & $+/-$ \\
\hline S5 & head & ++ & + & $+/-$ \\
\hline S6 & abdomen & ++ & + & $+/-$ \\
\hline S7 & head & ++ & ++ & - \\
\hline S8 & $\begin{array}{l}\text { Pectoral } \\
\text { region }\end{array}$ & ++ & + & $+/-$ \\
\hline S9 & $\operatorname{limb}$ & ++ & + & $+/-$ \\
\hline S10 & (para)-Genital & ++ & + & $+/-$ \\
\hline S11 & Limb & ++ & + & + \\
\hline S12 & abdomen & ++ & + & n.a. \\
\hline S13 & $\begin{array}{l}\text { Pectoral } \\
\text { region }\end{array}$ & ++ & ++ & $+/-$ \\
\hline S14 & head & ++ & + & + \\
\hline S15 & $\operatorname{limb}$ & ++ & ++ & - \\
\hline S16 & (para)-Genital & ++ & + & + \\
\hline S17 & Limb & ++ & + & $+/-$ \\
\hline S18 & abdomen & ++ & + & + \\
\hline S19 & $\begin{array}{l}\text { Pectoral } \\
\text { region }\end{array}$ & ++ & + & - \\
\hline S20 & neck & ++ & + & + \\
\hline S21 & $\operatorname{limb}$ & ++ & + & + \\
\hline S22 & (para)-Genital & ++ & ++ & n.a. \\
\hline S23 & Limb & ++ & + & $+/-$ \\
\hline S24 & abdomen & ++ & ++ & - \\
\hline S25 & $\begin{array}{l}\text { Pectoral } \\
\text { region }\end{array}$ & ++ & $+/-$ & $+/-$ \\
\hline N1 & head & $+/-$ & + & $+/-$ \\
\hline N2 & abdomen & $+/-$ & $+/-$ & - \\
\hline N3 & neck & $+/-$ & + & - \\
\hline N4 & $\operatorname{limb}$ & $+/-$ & $+/-$ & $+/-$ \\
\hline N5 & $\begin{array}{l}\text { Pectoral } \\
\text { region }\end{array}$ & $+/-$ & + & $+/-$ \\
\hline
\end{tabular}

$N$ Normal skin sample, $S$ sarcoid sample, n.a. not assessable; - negative staining; +/- weak immunolabelling; + moderate immunolabelling; ++ extensive and strong immunolabelling

was moderate in basal and parabasal layer of epidermis and in $20-50 \%$ of fibroblasts located immediately under the epidermis (Fig. 2e; secondary-only negative control Fig. 2f)), while the percentage of bcl-2 positive dermal fibroblasts was very low (10\%) (Fig. 2g; secondary-only negative control 


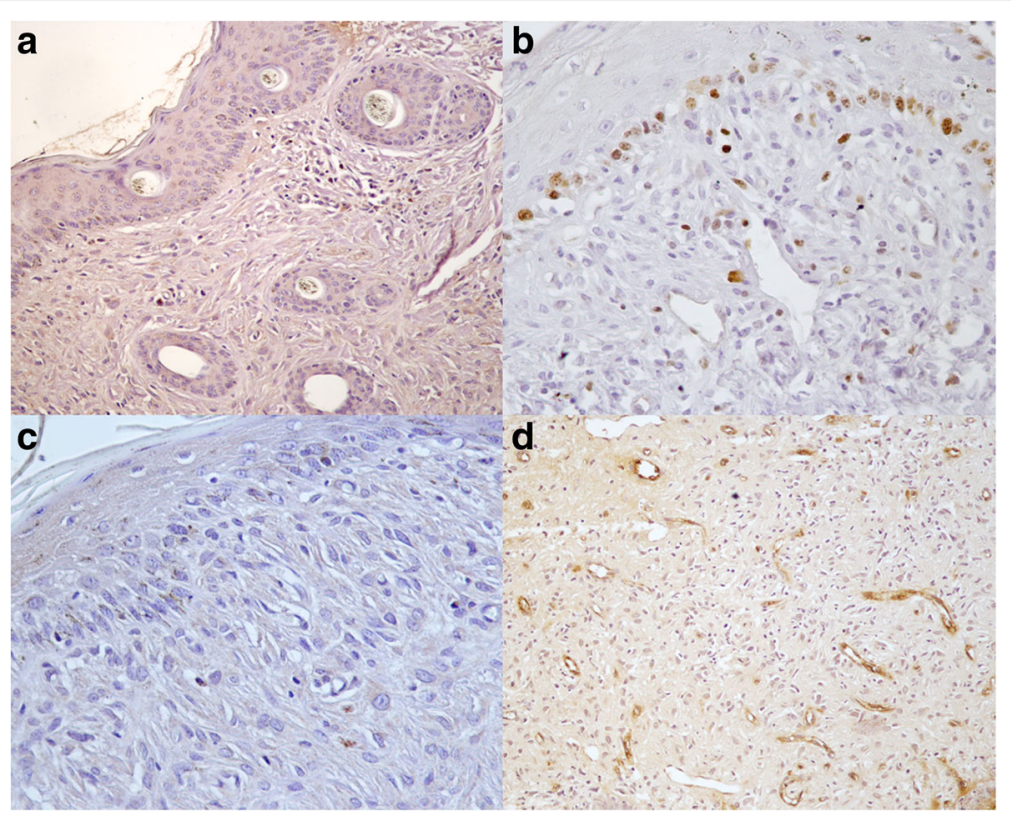

Fig. 1 Equine normal skin. Streptavidin-biotin-peroxidase stain. a weak granular cytoplasmatic VEGF immunostaining was detected in the basal layer of epidermis and hair follicle while normal fibroblasts were negative 20x; b Ki67 immunostaining was moderate and restricted to the basal layer of epidermis $40 x_{;} \mathbf{c}$ bcl-2 immunostaining was very weak and restricted to the basal layer of epidermis 40x; d blood vessels,

immunolabeled with VWF, appeared regular in shape, with a distinct lumen 20X

fig. h) and the intensity of staining was weak. Moreover, in all sarcoid samples, numerous small blood vessels often appeared irregular in shape (Fig. 2i; negative control Fig.l).

Microvessel density was lower in normal skin samples $(39.5 \pm 2.1)$ than in sarcoid samples $(84.8 \pm 65.06)$, with not statistically significant $p$ value $(p>0.05)$, while vascular parameters mean values (area and perimeter) were higher in normal skins $(418.02 \pm 84.14 ; 78.01 \pm 7.07)$ than in sarcoid samples $(223.08 \pm 55.92 ; 62.03 \pm 6.08)$, with statistically significant $p$ value $(p<0,05)$ (Table 2 ).

Western blotting analysis was performed to check the specificity of the antibodies used throughout the study (Fig. 3a-h). A band of the expected molecular size for VEGF (25 Kda), vWF (250 Kda), bcl-2 (26 Kda) and Ki67 (110 Kda) was identified in the tested samples as well as in Hela or Saos-2 cell lines used as positive control (Fig. 3a, c, e, f). The densitometric analysis of the bands normalized for $\beta$-actin revealed variable levels of VEGF protein among the samples, with higher expression in two sarcoid samples (Fig. 3b). Moreover, Von Willebrand factor protein was over-expressed in each sarcoid sample compared to each of normal skin lysates, in which the specific band was almost undetectable (Fig. 3d). The biochemical expression of bcl-2 and Ki67 was variable among the samples and no different trends between normal skin and tumor samples could be pointed out as confirmed by densitometric analysis and normalization for $\beta$-actin levels (Fig. 3f, h).

\section{Discussion}

VEGF is a potent angiogenic factor, produced by a variety of cell types, including keratinocytes, endothelial cells, macrophages, mast cells, fibroblasts $[29,34,35]$ and is involved in several types of tumors [23-27], where it has been shown to influence both tumor neovascularization and dissemination [36, 37]. Vascular endothelial growth factor can occur in at least six different isoforms, containing 121, 145, 165, 183, 189 and 206 amino acids. VEGF 121 is a freely diffusible isoform [38] and it has been proved to have a stronger angiogenic and tumorigenic activity when compared to the bigger isoforms [39-41].

In the present study, for the first time, we have demonstrated, by immunohistochemistry, the overexpression of VEGF (isoform 121) in equine sarcoid compared to normal skin, which was in part confirmed by biochemical analysis. It appeared as a strong and finely granular cytoplasmic staining pattern in the majority (>90\%) of keratinocytes, endothelial cells and sarcoid fibroblasts, suggesting a possible role in equine sarcoid development. Interestingly, in sarcoid samples we have also observed the presence of numerous small vessels, immunostained with vWF, which appeared often irregular in shape These findings were in agreement with other studies, which reported that tumor vasculature, formed under the influence of VEGF, is often structurally and functionally abnormal [42], probably as the results of the insufficient production or activation of other angiogenic factors, necessary for the formation of mature 


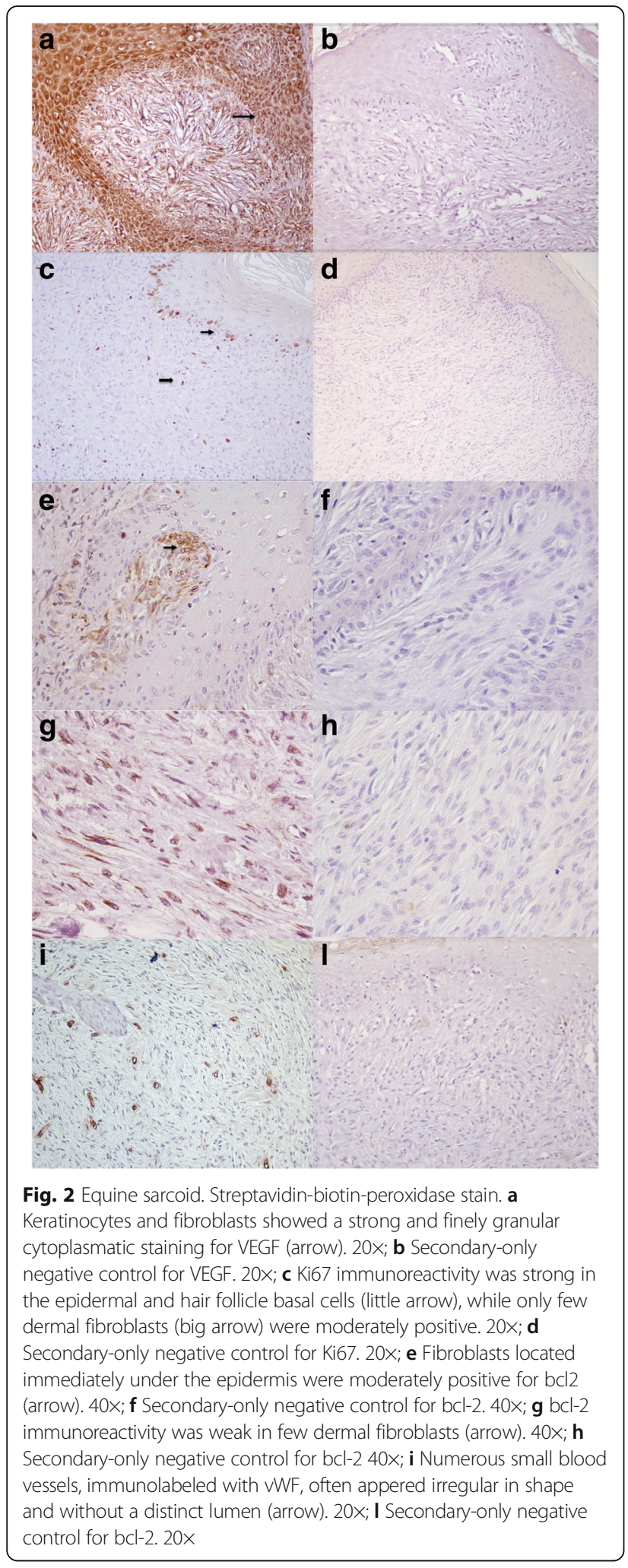

and functioning new vessels $[25,26]$. These data seem to strongly support the hypothesis that in sarcoid, a suboptimal blood flow could lead to a deficient oxygen gradient within the tissue that exacerbates angiogenesis [43]. It is well known that tissue mild hypoxia, an almost universal condition within wound healing, from which sarcoid could origin, is an effective inducer of VEGF synthesis [44]. Therefore, in sarcoid, a vicious circle may occur in which hypoxia upregulates VEGF synthesis, leading to an insufficient vascularization, which in turn probably exacerbates hypoxia. Despite numerous studies characterizing its angiogenic property, data on the role of VEGF in ECM homeostasis and remodeling are still scanty.

For this reason, we speculate that, in equine sarcoid, VEGF could be implicated not only in angiogenesis but also in ECM homeostasis and remodeling, through a deregulation of fibroblasts proliferation and apoptosis in a possible hypoxic condition. This mechanism was also reported during endochondral bone formation, in which VEGF couples hypertrophic cartilage remodeling, ossification and angiogenesis [21]. In this regard, a very low fibroblast growth rate has been reported in equine sarcoid, along with a low frequency of p53 mutations [45]. These last were generally associated with abnormalities in apoptotic pathways rather than abnormal cell cycle control mechanism [46].

In our sarcoids samples, the percentage of Ki67 positive fibroblasts ranged from 5 to $10 \%$ and, in agreement with previous studies [46-48], these results confirm that the rate of fibroblast proliferation in equine sarcoid was very low. Moreover, these observations correspond to the clinical evidence that equine sarcoids are slow growing tumors and can remain quiescent for years [47]. IHC and biochemical data did not prove an overall differential expression of Ki67 and bcl-2 in sarcoids compared to normal skin; however, the more frequent localization of BPV-positive cells, right near the dermo-epidermal junction $[49,50]$, could explain the higher expression of Ki67 and bcl-2 observed in epithelial portion and in dermo-epidermal junction.

\section{Conclusion}

Concluding, in this study we hypothesized that VEGF might have a role in sarcoid development, by altering ECM homeostasis, through a selection of a quiescent population of fibroblast, leading to an impaired degradation and excessive accumulation of ECM [14]. This also seems to be also supported by our previous study, which documented that the excessive and progressive deposition of connective tissue (collagen) in sarcoid is not only the result of elevated synthesis by fibroblasts, but it is also caused by a deficiency in matrix degradation due to an alterated expression of MMPs and TIMPs [15].

Currently, despite the numerous sarcoid treatment choices available, not all sarcoids are responsive. Hence, the importance of a better knowledge of equine sarcoid development. Further studies in the near future are needed to investigate the association between equine sarcoid and tissue 


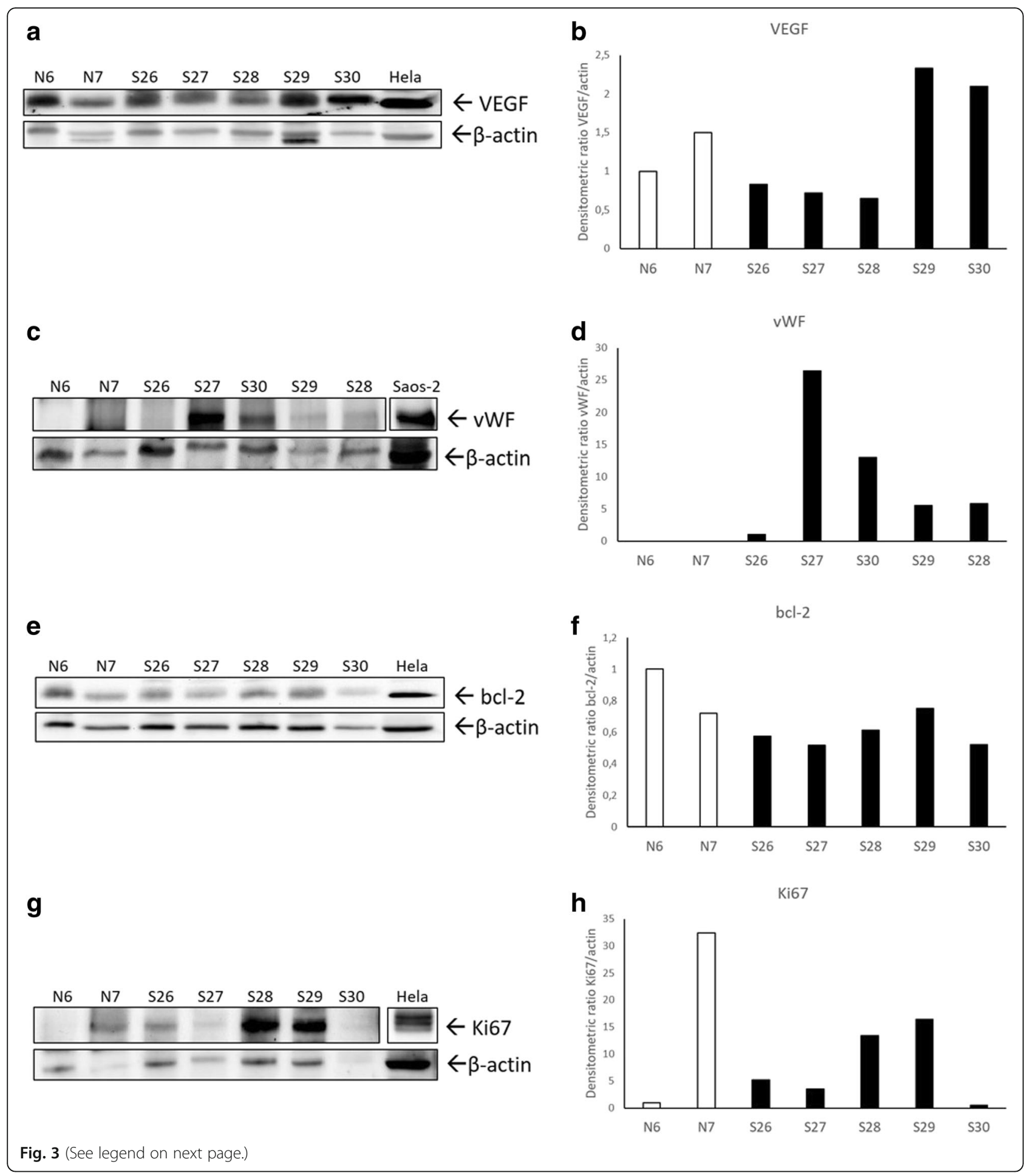


(See figure on previous page.)

Fig. 3 Western blotting analysis of VEGF, vWF, bcl-2 and Ki67 protein expression in equine sarcoids (S) and normal skin samples (N). a VEGF was expressed in all the analysed samples, with higher protein levels in S29 and S30. Hela whole cell lysate was run along with equine samples as positive control. The membrane was re-probed for $\beta$-actin to allow normalization. b Densitometric values were measured and expressed as VEGF/ actin ratio. c vWF was detectable in sarcoids but not in normal skin samples. Saos-2 whole cell lysate was run along with equine samples as positive control. The Saos-2 box is cut from the same membrane at a different exposure time and properly aligned according to the molecular standard loaded onto the gel. The membrane was re-probed for $\beta$-actin to allow normalization. $\mathbf{d}$ Densitometric values were measured and expressed as VWF/actin ratio. e bcl-2 was expressed at variable levels in the analysed samples. Hela whole cell lysate was run along with equine samples as positive control. The membrane was re-probed for $\beta$-actin to allow normalization. $\mathbf{f}$ Densitometric values were measured and expressed as bcl-2/actin ratio. $\mathbf{g}$ Variable expression of Ki67 protein in the analysed samples. Hela whole cell lysate was run along with equine samples as positive control. The Hela box is cut from the same membrane at a different exposure time and properly aligned according to the molecular standard loaded onto the gel. The membrane was re-probed for $\beta$-actin to allow normalization. $\mathbf{h}$ Densitometric values were measured and expressed as Ki67/actin ratio

hypoxia, which could have a crucial role for the development of new therapeutic strategies.

\section{Methods}

\section{Tumor samples}

A total of 25 (S1-S25) equine sarcoids (each from a different horse), clinically identified based on their gross morphology according to Pascoe and Knottenbelt [51], were obtained from affected horses, which underwent surgery routinely, adhering to a high standard (best practice) of veterinary care, after informed written consent of the owners, and according to Directives 2010/63/EU (art. 1 c. 4) and 2010/63/ EU. Tumors were localized on the neck (2), limbs (8), pectoral region (5), head (3), abdomen (4), (para)-genital (3) (Table 1). Sarcoid tissues used in this study were known to be BPV positive [48].

As controls, tissues from 5 normal skin BPV positive samples (N1-N5), were taken during necropsy from five healthy horses. We did not seek committee approval as all samples analyzed were not collected as part of experimental clinical veterinary practices but as routine diagnosis and treatment, according to Directive 2010/63/EU (art. 1 c. 4 ) on protection of animals used for scientific purposes. All samples were $10 \%$ formalin fixed, paraffin-embedded for routine histological processing and stained with haematoxylin and eosin for light microscopy study.

Table 2 Microvessel density and vascular parameters (areas and perimeters), expressed as mean (X) and standard deviation (SD), in equine sarcoids and normal skins

\begin{tabular}{llll}
\hline & $\begin{array}{l}\text { Normal skin } \\
(\mathrm{X} \pm \mathrm{SD})\end{array}$ & $\begin{array}{l}\text { Equine sarcoids } \\
(\mathrm{X} \pm \mathrm{SD})\end{array}$ & $\begin{array}{l}p \text { values } \\
(<0,05)\end{array}$ \\
\hline Microvessel density & $39.5 \pm 2.1$ & $84.8 \pm 65.06$ & 0,3 \\
Areas $\left(\mathrm{mm}^{2}\right)$ & $418.02 \pm 84.14$ & $223.08 \pm 55.92$ & 0,001 \\
Perimeters $(\mathrm{mm})$ & $78.01 \pm 7.07$ & $62.03 \pm 6.08$ & 0,007 \\
\hline
\end{tabular}

Additional five sarcoids (S26-S30) and 2 normal skin samples (N6-N7) were collected as above and immediately frozen at $-80{ }^{\circ} \mathrm{C}$ in order to allow Western blotting analysis.

\section{Immunohistochemistry}

Paraffin sections of equine sarcoids (S1-S25) and normal skin (N1-N5) from healthy horses were dewaxed in xylene, dehydrated in graded alcohols and washed in $0.01 \mathrm{M}$ phosphate-buffered saline (PBS), $\mathrm{pH}$ 7.2-7.4. Endogenous peroxidase was blocked with hydrogen peroxide $0.3 \%$ in absolute methanol for $30 \mathrm{~min}$. The immunohistochemical procedure (streptavidin biotin-peroxidase method) for the detection of VEGF, bcl-2, Ki67 and vWF was the same as that used by the authors in a previous study [15]. The immunolabelling procedure included negative control sections incubated with PBS instead of the primary antibodies (Fig. 2b, d, f, h, l). Primary antibodies, dilutions and antigen retrieval techniques used in this study are listed in Table 3. Primary antibodies were diluted in phosphate-buffered saline (PBS) and applied overnight at $4{ }^{\circ} \mathrm{C}$. After 2 washes in PBS, MACH 1 mouse probe (Biocare Medical, LLC, Concord, CA, USA) was applied for $20 \mathrm{~min}$ at room temperature. After, MACH-1 Universal HPR-Polymer (Biocare Medical) was applied for $30 \mathrm{~min}$ at room temperature. To reveal immunolabelling, diaminobenzidinetetrahydrochloride was used as a chromogen, and haematoxylin as counterstain.

\section{Scoring of immunoreactivity}

The intensity of immunolabelling in each specimen, for each antibody, was scored by two independent observers (MM and KP) under blinded conditions, as performed in a previous study [52]. Briefly, for each sample the immunoreactivity was scored from negative to strong, as follows: n.a., not assessable; - negative staining; +/- weak immunolabelling; + moderate immunolabelling; ++ extensive and strong immunolabelling. Moreover, the number of positively-labelled cells was established by counting 1.000 cells in 10 fields 
Table 3 List of primary antibodies used for immunohistochemistry and western blotting analysis

\begin{tabular}{lllllll}
\hline Antibody & Manufacturer & Clone & Host species & Antigen retriever & IHC Dilution & WB Dilution \\
\hline vWF & DAKO & Polyclonal & Rabbit & 0.05\% pepsin in 0.01 M HCl (pH 2) at 37 ${ }^{\circ} \mathrm{C}$ for 15 min & $1: 400$ & $1: 1000$ \\
bcl-2 & DAKO & 124 & mouse & Heated Citrate buffer, ph 6.0, 30 min & $1: 100$ & $1: 1000$ \\
VEGF & Thermoscientific & JH121 & mouse & Heated Citrate buffer, ph 6.0, 30 min, & $1: 200$ & $1: 200$ \\
Ki67 & Santa Cruz & D-6 & mouse & Heated Citrate buffer, ph 6.0, 30 min, & $1: 100$ & $1: 1000$ \\
\hline
\end{tabular}

at $400 \times$ magnification (40× objective $10 \times$ ocular) and results were expressed as percentage.

\section{Microvessel density and vascular parameter measurements} Microvessel density (number of vessels per $\mathrm{mm}^{2}$ ) and vascular parameter measurements (vessel area and perimeter) were performed on vWF immunostained sections, using a free image analysis software (Image J). For each tumor 10 fields, randomly selected, were captured at $400 \times$ magnification (40x objective $10 \times$ ocular) with a microscope (E-400; Nikon Eclipse, Tokyo, Japan) coupled to a videocamera (TKC1380E; JVC, Tokyo, Japan), stored in the digital memory, and shown on the monitor. The fields were examined and manual outlining of immunolabelled microvessels was performed; microvessel density, areas, perimeters were then calculated based on image analysis, and results were expressed as mean $(\mathrm{X})$ and standard deviation values $( \pm \mathrm{SD})$ (Table 2). Statistical assessment was performed using a Student $\mathrm{t}$-test by analysis of variance (ANOVA) and $p$-value $<$ 0.05 with $95 \%$ confidence interval $(\mathrm{CI})$ was considered statistically significant.

\section{Protein extraction and SDS PAGE/western blotting}

Tissue samples N6-N7 and T26-T30 were homogenized in ice-cold RIPA buffer (50 mM Tris-HCl, pH 7.5, $150 \mathrm{mM}$ $\mathrm{NaCl}, 1 \%$ Triton X100, 1 mM EDTA, deoxycholate 0.25\%) added with phosphatase and protease inhibitor cocktails (Sigma-Aldrich, Milan, Italy) by using TissueLyser machinery (Qiagen, Milan, Italy) according to manufacturer's protocol. Tissue homogenates were incubated on a rocking wheel for $30^{\prime}$ at $4{ }^{\circ} \mathrm{C}$. Protein extracts were clarified by high-speed centrifugation at $4{ }^{\circ} \mathrm{C}$ for $30^{\prime}$ and total proteins were quantified by Bradford assay (Bio-Rad, Bio-Rad Laboratories, Segrate (MI), Italy). Equal amounts of lysates were resuspended in Laemmli sample buffer (Bio-Rad), boiled and analyzed by denaturing polyacrylamide gel electrophoresis (SDS PAGE). Proteins were blotted from gel onto nitrocellulose membranes using TransBlot Turbo apparatus (Bio-Rad, Bio-Rad Laboratories, Segrate (MI), Italy). The membranes were blocked with $5 \%$ non-fat dry milk in Tris buffered saline (10 mM Tris-HCl, pH 7.4, $165 \mathrm{mM}$ $\mathrm{NaCl}$ ) with $0.1 \%$ tween (TTBS), for $1 \mathrm{~h}$ (h) at room temperature (RT) and incubated over night at $4{ }^{\circ} \mathrm{C}$ with the primary antibodies at the indicated dilutions: anti- $\mathrm{Bcl} 2$ (1:1000), anti-VEGF (1:200), anti-Ki67 (1:1000), anti-vWF (1:1000). After four washing steps of 10 minutes, appropriate peroxidase-conjugated secondary antibodies were applied for $1 \mathrm{~h}$ at RT at 1:2000 dilution. Following further four washings in TTBS, bound antibodies were visualized by enhanced chemiluminescence (Cyanagen, Bologna, Italy). The blots were stripped and reprobed against mouse anti- $\beta$-actin antibody (CP01, Calbiochem, San Diego, CA, USA) (1:500) to allow normalization. Protein levels were quantitatively estimated by densitometric analysis using ChemiDoc gel scanner (Bio-Rad) equipped with a densitometric workstation (Image Lab software, (Bio-Rad Laboratories, Segrate (MI), Italy). Proteins concentrations were normalized to the $\beta$-actin levels.

\section{Abbreviations \\ bcl-2: B-cell lymphoma 2; BPV: Bovine papillomavirus; BPV-2: Bovine papillomavirus type-2; ECM: Extracellular Matrix; MMP: matrix metalloproteinase; N: normal skin; PBS: phosphate-buffered saline; PDGF: platelet-derived growth factor; S: samples T: sarcoid samples; TIMP: Tissue inhibitor of metalloproteinase; VEGF: Vascular endothelial growth factor; vWF: Von Willebrandt factor}

\section{Acknowledgements}

The authors thank Mr. Raffaele Ilsami (Department of Veterinary medicine and animal production) for his technical assistance, and Dr. Tommaso De Palma (veterinarian) for providing some sarcoid samples.

\section{Funding}

The authors received financial support from the research funding of the Department of Veterinary medicine and animal production, University of Naples, Italy.

\section{Availability of data and materials}

The datasets and materials used and analyzed during the current study are available from the bank of our Pathological Anatomy Laboratory (Department of Veterinary Medicine and Animal Productions, University of Naples, Italy), with an identification code.

\section{Authors' contributions}

PM has conceived the study, coordinated the group and drafted the manuscript; MM together with PM, has participated in the conception and design of the study, in analysis and interpretation of histological and immunohistochemical data and drafted the manuscript; BR and GB have been involved in revising the manuscript for important intellectual content: IP and KP carried out the histological and immunohistochemical studies, taking part in western blotting analysis; GA and IP carried out the molecular studies, taking part in western blotting analysis. All authors read and approved the final manuscript.

\section{Author's information}

MM is employed as a researcher at the Department of Veterinary medicine and animal production; BR and GB are employed as associate professors at the Department of Veterinary medicine and animal production; PM is employed as a full professor at the Department of Veterinary medicine and animal production; IP is a student trainee for the degree thesis; GA is a postdoc research fellow at Department of Veterinary medicine and animal production; KP is PhD fellow at Department of Veterinary medicine and animal production. 


\section{Ethics approval and consent to participate}

This is a non-experimental research on owned animals, affected by spontaneous tumors, surgically excised as routine diagnosis and treatment, after informed written consent obtained from owners, adhering to a high standard (best practice) of veterinary care, and according to Directives 2010/63/EU (art. 1 C. 4) and 2010/63/EU.

\section{Consent for publication}

Not applicable.

\section{Competing interests}

The authors declare that they have no competing interests.

\section{Publisher's Note}

Springer Nature remains neutral with regard to jurisdictional claims in published maps and institutional affiliations.

\section{Received: 22 December 2017 Accepted: 16 August 2018} Published online: 03 September 2018

\section{References}

1. Jackson C. The incidence and pathology of tumours of domesticated animals in South Africa. Onderstepoort J Vet Sci Anim Ind. 1936;6:375-85.

2. Pascoe RR, Summers PM. Clinical survey of tumours and tumor like lesions in horses in southeast. Equine Vet J. 1981;13:325-9.

3. Ragland WL, Keown GH, Spencer GR. Equine sarcoid. Equine Vet J. 1970;2:2-11.

4. Lavach JD, Sullins KE, Roberts SM, Severin GA, Wheeler C, Leuker DC. BCG treatment of periocular sarcoid. Equine Vet J. 1985;17:445-8.

5. Knottenbelt DC. A suggested clinical classification of the equine sarcoid. Clin Tech Equine Pract. 2005;4:278-95.

6. Borzacchiello G, Corteggio A. Equine sarcoid: state of the art. Ippologia. 2009;20:7-14.

7. Nasir L, Campo MS. Bovine papillomaviruses: their role in the aetiology of cutaneous tumours of bovids and equids. Vet Dermatol. 2008;19:243-54.

8. Nasir L, Brandt S. Papillomavirus associated diseases of the horse. Vet Microbiol. 2013;167(Suppl 1-2):159-67.

9. Borzacchiello G, Roperto F. Bovine papillomaviruses, papillomas and cance in cattle. Vet Res. 2008;39:45

10. Lunardi M, Alcântara B, Otonel R, Rodrigues W, Alfieri A, Alfieri A. Bovine papillomavirus type 13 DNA in equine sarcoids. J Clin Microbiol. 2013;51:2167-71

11. Chambers G, Ellsmore VA, O'Brien PM, Reid SW, Love S, Campo MS, Nasir L. Association of bovine papillomavirus with the equine sarcoid. J Gen Virol. 2003:84:1055-62.

12. Potocki L, Lewinska A, Klukowska-Rötzler J, Bielak-Zmijewska A, Grabowska W, Rzeszutek I, Kaminska P, Roga E, Bugno-Poniewierska M, Slota E, Mählmann K, Koch C, Wnuk M. Sarcoid-derived fibroblasts: links between genomic instability, energy metabolism and senescence. Biochimie. 2014;97:163-72.

13. Potocki L, Lewinska A, Klukowska-Rötzler J, Bugno-Poniewierska M, Koch C, Mählmann K, Janda J, Wnuk M. DNA hypomethylation and oxidative stressmediated increase in genomic instability in equine sarcoid-derived fibroblasts. Biochimie. 2012;94(9):2013-24.

14. Cochrane AC. Models in vivo of wound healing in the horse and the role of growth factors. Vet Dermatol. 1997;8:259-72

15. Martano M, Corteggio A, Restucci B, De Biase ME, Borzacchiello G, Maiolino $P$. Extracellular matrix remodeling in equine sarcoid: an immunohistochemical and molecular study. BMC Vet Res. 2016:12:24.

16. Neve A, Cantatore FP, Maruotti N, Corrado A, Ribatti D. Extracellular matrix modulates angiogenesis in physiological and pathological conditions. Biomed Res Int. 2014;2014:756078.

17. Raza SL, Cornelius LA. Matrix metalloproteinases: pro- and anti-angiogenic activities. J Investig Dermatol Symp Proc. 2000;5(1):47-54.

18. Cornelius LA, Nehring LC, Roby JD, Parks WC, Welgus HG. Human dermal microvascular andothelial cells produce matrix metalloproteinases in response to agiogenic factors and migration. J Invest Dermatol. 1995;105(2):170-6.

19. Ucuzian AA, Gassman AA, East AT, Greisler HP. Molecular mediators of angiogenesis. J Burn Care Res. 2010;31(1):158.

20. Reichardt LF, Tomaselli KJ. Extracellular matrix molecules and their receptors: functions in neural development. Annu Rev Neurosci. 1991;14:531-70.
21. Gerber HP, Vu TH, Ryan AM, Kowalski J, Werb Z, Ferrara N. VEGF couples hypertrophic cartilage remodeling, ossification and angiogenesis during endochondral bone formation. Nat Med. 1999;5:623-8.

22. Chintalgattu V, Nair DM, Katwa LC. Cardiac myofibroblasts: a novel source of vascular endothelial growth factor (VEGF) and its receptors Flt-1 and KDR. J Mol Cell Cardiol. 2003;35:277-86.

23. Maiolino P, De Vico G, Restucci B. Expression of vascular endothelial growth factor in basal cell tumours and in squamous cell carcinomas of canine skin. J Comp Pathol. 2000;123(2-3):141-5.

24. Restucci B, Papparella S, Maiolino P, De Vico G. Expression of vascular endothelial growth factor in canine mammary tumors. Vet Pathol. 2002;39(4):488-93.

25. Restucci B, Maiolino P, Paciello O, Martano M, De Vico G, Papparella S. Evaluation of angiogenesis in canine seminomas by quantitative immunohistochemistry. J Comp Pathol. 2003:128(4):252-9.

26. Restucci B, Borzacchiello G, Maiolino P, Martano M, Paciello O, Papparella S. Expression of vascular endothelial growth factor receptor Flk-1 in canine mammary tumours. J Comp Pathol. 2004;130(2-3):99-104.

27. Martano M, Restucci B, Ceccarelli DM, Lo Muzio L, Maiolino P. Immunohistochemical expression of vascular endothelial growth factor in canine oral squamous cell carcinomas. Oncol Lett. 2016;11(1):399-404.

28. Lee SH, Jeong D, Han YS, Baek MJ. Pivotal role of vascular endothelia growth factor pathway in tumor angiogenesis. Ann Surg Treat Res. 2015;89(1):1-8

29. Dvorak HF, Detmar M, Claffey KP, Nagy JA, van de Water L, Senger DR. Vascular permeability factor/vascular endothelial growth factor: an important mediator of angiogenesis in malignancy and inflammation. Int Arch Allergy Immunol. 1995;107:233-5.

30. Dvorak HF. Rous-Whipple Award Lecture. How tumors make bad blood vessels and stroma. Am J Pathol. 2003;162(6):1747-57.

31. López-Ocejo O, Viloria-Petit A, Bequet-Romero M, Mukhopadhyay D, Rak J, Kerbel RS. Oncogenes and tumor angiogenesis: the HPV-16 E6 oncoprotein activates the vascular endothelial growth factor (VEGF) gene promoter in a p53 independent manner. Oncogene. 2000;19(40):4611-20.

32. Li G, He L, Zhang E, Shi J, Zhang Q, Le AD, Zhou K, Tang X. Overexpression of human papillomavirus (HPV) type 16 oncoproteins promotes angiogenesis via enhancing HIF-1a and VEGF expression in non-small cell lung cancer cells. Cancer Lett. 2011;311(2):160-70.

33. Shao JS, Shiyu Wang JS, Chung K, Du JT, Wang J, Qiu X-S, Wang E-H, Guang-Ping W. HPV16 E6/E7 upregulates HIF-2a and VEGF by inhibiting LKB1 in lung cancer cells. Tumour Biol. 2017;39(7):1010428317717137.

34. Ferrara N, Davis-Smyth T. The biology of vascular endothelial growth factor. Endocr Rev. 1997:18:4-25.

35. Frank S, Hubner G, Breier G, Longaker MT, Greenhalgh DG, Werner S. Regulation of vascular endothelial growth factor expression in cultured keratinocytes. Implications for normal and impaired wound healing. J Biol Chem. 1995:270:12607-13.

36. Naumov GN, Akslen LA, Folkman J. Role of angiogenesis in human tumor dormancy: animal models of the angiogenic switch. Cell Cycle. 2006;5(16):1779-87.

37. Folkman J. Role of angiogenesis in tumor growth and metastasis. Semin Oncol 2002; (6 Suppl 16):15-18.

38. Park JE, Keller GA, Ferrara N. The vascular endothelial growth factor (VEGF) isoforms: differential deposition into the subepithelial extracellular matrix and bioactivity of extracellular matrix-bound VEGF. Mol Biol Cell. 1993;4(12):1317-26.

39. Zhang HT, Scott PA, Morbidelli L, Peak S, Moore J, Turley H, Harris AL, Ziche M, Bicknell R. Br J Cancer. 2000;83(1):63-8.

40. Jacobsen J, Grankvist K, Rasmuson T, Bergh A, Landberg G, Ljungberg B. Expression of vascular endothelial growth factor protein in human renal cell carcinoma. BJU Int. 2004;93:297-302.

41. van der Loos CM, Meijer-Jorna LB, Broekmans MEC, Ploegmakers HP, Teeling $\mathrm{P}$, de Boer OJ, van der Wal AC. Anti-human vascular endothelial growth factor (VEGF) antibody selection for Immunohistochemical staining of proliferating blood vessels. J Histochem Cytochem. 2010;58(2):109-18.

42. Nagy JA, Chang SH, Dvorak AM, Dvorak HF. Why are tumour blood vessels abnormal and why is it important to know? Br J Cancer. 2009;100(6):865-9.

43. Deschene K, Céleste C, Boerboom D, Theoret CL. Hypoxia regulates the expression of extracellular matrix associated proteins in equine dermal fibroblasts via HIF1. J Dermatol Sci. 2012:65(1):12-8.

44. Bao P, Kodra A, Tomic-Canic M, Golinko MS, Ehrlich HP, Brem H. The role of vascular endothelial growth factor in wound healing. J Surg Res. 2009;153:347-58. 
45. Bucher K, Szalai G, Marti E, Griot-Wenk ME, Lazary S, Pauli U. Tumour suppressor gene p53 in the horse: identification, cloning, sequencing and possible role in the pathogenesis of equine sarcoid. Res Vet Sci. 1996;61(2):114-9.

46. Nixon C, Chambers G, Ellsmore V, Campo MS, Burr P, Argyle DJ, Reid SW, Nasir L. Expression of cell cycle associated proteins cyclin a, CDK-2, p27kip1 and p53 in equine sarcoids. Cancer Lett. 2005;221(2):237-45.

47. Martens A, Moor ADE, Demeulemeester J, Ducatelle R. Histopathological characteristics of five clinical types of equine sarcoid. Res Vet Sci. 2000; 69(Suppl3):295-300.

48. Borzacchiello G, Russo V, Della Salda L, Roperto S, Roperto F. Expression of platelet-derived growth factor- $\beta$ receptor and bovine papillomavirus E5 and E7 Oncoproteins in equine sarcoid. J Comp Pathol. 2008;139(4):231-7.

49. Lory S, von Tscharmer C, Marti E, Bestetti G, Grimm S, Waldvogel A In situ hybridization of equine sarcoids with bovine papilloma virus. Vet Rec. 1993;132:132-3.

50. Teifke JP, Hardt M, Weiss E. Detection of bovine papillomavirus DNA in formalin-fixed and paraffin-embedded equine sarcoids by polymerase chain reaction and non-radioactive in situ hybridization. Eur J Vet Pathol. 1994;1:5-10.

51. Pascoe RR, Knottenbelt DC. Manual of Equine Dermatology pub. London: WB Saunders; 1999. p. 244-50.

52. Salem A, Assaf M, Helmy A, Nofal A, Ibrahim S, Eldeeb F, Youssef C. Role of vascular endothelial growth factor in keloids: a clinicopathologic study. Int J Dermatol. 2009;48(10):1071-7.

Ready to submit your research? Choose BMC and benefit from:

- fast, convenient online submission

- thorough peer review by experienced researchers in your field

- rapid publication on acceptance

- support for research data, including large and complex data types

- gold Open Access which fosters wider collaboration and increased citations

- maximum visibility for your research: over $100 \mathrm{M}$ website views per year

At BMC, research is always in progress.

Learn more biomedcentral.com/submissions 